\title{
SOBRE PEDRAS NO MEIO DO CAMINHO: TEORIAS DE ALFABETIZAÇÃO E PRÁTICAS DE LETRAMENTO NA FORMAÇÃO DE PROFESSORES
}

\section{ON STONES IN THE MIDDLE OF THE PATH: THEORIES ON BEGINNING LITERACY AND LITERACY PRACTICES IN TEACHERS EDUCATION}

\author{
Gabriela Medela da SILVA \\ Universidade do Estado do Rio de janeiro \\ gabimedela@hotmail.com \\ Marcia Lisbôa Costa de OLIVEIRA \\ Universidade do Estado do Rio de janeiro \\ lisboamarcia@hotmail.com
}

Resumo: Pensando os caminhos da formação de alfabetizadores no Brasil, a partir das tensões entre teorias e práticas, o presente estudo articula-se em torno da hipótese de que para a superação dos problemas concernentes à alfabetização e ao letramento nas séries iniciais de muitas escolas públicas brasileiras é necessário construir modelos de formação de professores que configurem propostas contínuas, sistemáticas, situadas e fundamentadas de teoria-na-prática, de modo a favorecer a autonomia e a autoria dos docentes. Partimos do pressuposto de que a superficialidade teórica que tende a caracterizar os cursos de formação continuada de professores gerou a má compreensão de conceitos teóricos advindos dos campos da psicogênese e dos estudos do letramento e provocou o processo que Magda Soares nomeou como "desinvenção da alfabetização" (2003, p.1). Esse processo de perda de especificidade do ensino do sistema alfabético é um dos elementos contextuais que explicam a ênfase no trabalho com texto e o abandono da sistematização do ensino da escrita e da leitura. Para demonstrar como isso ocorreu, a proposta deste texto é percorrer análises de diferentes estudiosos, como Soares, Colello, Morais, Botero, Ferreiro, Freire, Mortatti e Kleiman, entre outros, tecendo um panorama das teorias sobre letramento e alfabetização em circulação a partir dos anos 80 e tentando entender como as frequentes discussões sobre a necessidade de letrar levaram ao apagamento da alfabetização, entendida como processo de ensino/aprendizagem do sistema alfabético. Ao final, apresentamos uma proposta para a formação de professores que considere a escola como espaço de produção do conhecimento e seja fundada em uma perspectiva da teoria-na-prática. 
Palavras-chave: alfabetização; letramento; formação de professores; teoria-naprática.

Abstract: Reflecting on the paths of teacher education in Brazil from the tensions between theories and practices, this paper is based on the hypothesis that, in order to overcome the problems concerning literacy and literacy in the initial grades of many Brazilian public schools, it is necessary to bult a model of teacher training that sets up a continuous, systematic, situated and grounded theory-in-practice proposal , in order to favor the autonomy and the authorship of the teachers.. We start from the assumption that the theoretical superficiality that tends to characterize teacher training programs generated the misunderstanding of theoretical concepts coming from the fields of the psychogenesis and the studies of the literacy and they provoked a process that Magda Soares called "desinvention of alphabetization" (2003, p.1). This process of loss of the specificity of the teaching of the alphabetical system is a contextual elements that explain the emphasis in the with text and the abandonment of systematization of the teaching/learning of writing and reading. In order to demonstrate how this occurred, the proposal of this text is to analyze opinions from different scholars, such as Soares, Colello, Morais, Botero, Ferreiro, Freire, Mortatti and Kleiman, among others, providing a panorama of the theories about alphabetization and literacy in circulation from of the 1980s and trying to understand how the discussions on literacy led to the erasure of the study of the alphabetic system. In the end, we present a proposal for the formation of teachers that considers the school as a space that produces of knowledge and is based on a theory-in-practice perspective. Keywords: literacy; literacy; teacher training; theory-in-practice.:

\section{Introdução}

Em meio a teorias, polêmicas sobre métodos, propagandas de livros didáticos, campanhas nacionais de alfabetização, cursos e "formações", diretrizes curriculares e outros discursos, os professores alfabetizadores foram muitas vezes levados a trilhar caminhos que não dominavam, seguindo a tendência teórica ou metodológica do momento, assim, sua identidade ficou fragilizada e sua autonomia enfraquecida. 
Nesse texto, desenvolvemos uma reflexão sobre os discursos que vem influenciando a formação dos alfabetizadores e suas repercussões na práticas pedagógicas e nos resultados educacionais. Percorremos teorias sobre letramento e alfabetização em circulação a partir dos anos 80, para entender como as frequentes discussões sobre a necessidade de letrar os alunos, principalmente nas séries iniciais, acabaram por criar uma forte preocupação quanto à promoção do letramento e, dessa forma, a alfabetização, entendida como processo de aprendizagem do sistema alfabético, perdeu muito espaço.

Considerando que os professores precisam exercer sua autonomia com autoria, pretendemos neste texto discutir a hipótese de que teorias e metodologias difundidas de forma superficial e institucionalizadas em documentos oficiais contribuíram para o agravamento dos problemas no que se refere ao ensino/aprendizagem do sistema da escrita alfabética e das práticas sociais letramento.

Consideramos que somente a promoção de um modelo de formação de professores que desenvolva uma proposta contínua, sistemática, situada e plural, com experiências de teoria-na-prática, pode mudar o cenário da alfabetização no Brasil, possibilitando a cada alfabetizador a construção do seu caminho teóricometodológico.

\section{A questão dos métodos de alfabetização e a emergência do "construtivismo"}

Em nosso país, segundo Mortatti (2006, p.1), a história da alfabetização está intimamente relacionada à história dos métodos de alfabetização que, desde o final do século XIX, vêm gerando tensas disputas relacionadas com "antigas" e "novas" explicações para a dificuldade que nossas crianças apresentam para aprender a ler e a escrever.

Por muito tempo, até meados dos anos 1980, a discussão referente às práticas de alfabetização relacionava-se ao debate sobre os métodos mais eficazes para ensinar a ler e a escrever: sintéticos, analíticos e analítico-sintéticos (ALBUQUERQUE, 2012, p.7). Reinavam, então, no cenário educacional os chamados "métodos tradicionais de ensino", que começaram a se desenvolver na Europa a partir 
do século XVII em um contexto de mudanças históricas orientadas por novos modelos sociais que passaram a demandar a leitura e a escrita em uma época em que a maioria da população ainda era analfabeta (ALBUQUERQUE, 2012, p.7). No entanto, a partir dos anos 1960, esse modelo "tradicional" passou a ser duramente criticado, visto que as inúmeras mudanças sociais e econômicas observadas na sociedade capitalista exigiram das escolas o desenvolvimento de uma nova proposta pedagógica, a qual possibilitasse aos indivíduos o uso funcional da escrita (LEITE, 2010, p. 20).

A urgência por mudanças nas práticas de ensino era evidenciada nas taxas de analfabetismo que, embora apresentassem uma involução percentual, segundo Rojo (2009, p. 18), de acordo com os dados censitários, indicavam, na verdade, que nossa população analfabeta havia crescido de cerca de sete milhões de pessoas acima de 5 anos de idade, em 1880, para 32,7 milhões de analfabetos em 1980. Isso demonstra quão ineficientes eram os métodos de ensino tradicionais que, sem dúvidas, favoreciam a exclusão e a desigualdade social. Nesse contexto, a psicogênese acabou sendo considerada uma maneira de acabar com um problema crescente. Assim,

Como correlato teórico- metodológico da busca de soluções para esse problema, introduziu-se no Brasil o pensamento construtivista de alfabetização, resultante das pesquisas sobre a psicogênese da língua escrita desenvolvidas pela pesquisadora argentina Emília Ferreiro e colaboradores. Deslocando o eixo das discussões dos métodos de ensino para o processo de aprendizagem da criança (sujeito cognoscente), o construtivismo se apresenta, não como um método novo, mas como uma "revolução conceitual", demandando, dentre outros aspectos, abandonarem-se as teorias e práticas tradicionais, desmetodizar-se o processo de alfabetização e se questionar a necessidade das cartilhas (MORTATTI, 2006, P.10).

Ante a possibilidade de sucesso, amparada nos estudos de Emília Ferreiro e Ana Teberosky, a apropriação da escrita alfabética passou a ser tratada como um percurso evolutivo, por meio de atividades que levassem o aluno a refletir sobre o sistema de escrita. Este deixou de ser compreendido como um código, o qual se aprenderia a partir de atividades de repetição e memorização, passando a ser compreendido como um sistema notacional (alfabético). Houve então um progressivo desinvestimento no estudo de métodos de ensino, também chamado de "desmetodização" e, aos poucos, a concepção de alguns professores mudou:

Eles perceberam, por meio de pesquisas, que, no processo de apropriação do Sistema de Escrita Alfabética, os alunos precisariam entender como esse sistema funciona. Para isso, é fundamental que compreendam o que a escrita nota (ou "representa", "grafa") e como a escrita 
cria essas notações (ou "representações"). Eles precisariam, portanto, entender que o que a escrita alfabética nota no papel são os sons das partes das palavras e que o faz considerando segmentos sonoros menores que a sílaba (os fonemas) (ALBUQUERQUE, 2012, P.16).

Esses métodos apresentavam divergências quanto ao ponto de partida para o ensino da leitura e da escrita (de unidades menores da língua para as maiores ou o inverso), mas, possuíam em comum a concepção de leitura e escrita como decodificação e codificação, além de apresentarem uma mesma teoria de conhecimento subjacente: a visão empirista/ associacionista de aprendizagem. Neles, a aprendizagem é vista como um processo de simples acumulação das informações recebidas do exterior, sem que o sujeito precise, em sua mente, reconstruir esquemas ou modos de pensar, para poder compreender os conteúdos (sobre letras e sons) que alguém (a escola, a professora) estava Ihe transmitindo (MORAIS, 2012, p.27).

Segundo Mortatti (2006, p, 3), desde a época da implantação do modelo republicano de escola, observam-se repetidos esforços de mudança, a partir da necessidade de superação daquilo que, em cada momento histórico, considerava-se tradicional nesse ensino e fator responsável pelo seu fracasso.

Na década de 60, Paulo Freire já denunciava as práticas de ensino alienantes da "educação bancária" (aquela em que, nos alunos, professores depositam conhecimentos), inaugurando uma concepção libertadora de aprendizagem, marcada pela consciência e pela possibilidade de transformar o mundo, por meio de

“/.../ uma concepção de educação, que the propiciasse a reflexão sobre seu próprio poder de refletir e que tivesse sua instrumentalidade, por isso mesmo, no desenvolvimento desse poder, na explicitação de suas potencialidades, de que decorreria sua capacidade de opção. Educação que levasse em consideração os vários graus de poder de captação do homem brasileiro da mais alta importância no sentido de sua humanização (FREIRE, 1967, P. 57).

Com o passar do tempo, pesquisas como a de Freire, que evidenciavam uma concepção de alfabetização que se estende muito além do domínio de um código, foram se tornando cada vez mais comuns, ao passo que na década de 80 houve grande abertura para publicações, estudos e discussões sobre a Teoria Construtivista de Jean Piaget, as teorias sócio-interacionistas de Vygotsky e Henri Wallon, e os estudos de Emília Ferreiro e Ana Teberosky sobre a psicogênese da língua escrita. Tais estudos, voltados para a compreensão de como o sujeito aprende, alteraram profundamente a concepção do processo da representação da língua escrita, pela criança, trazendo contribuições de extrema relevância para o campo educacional, 
visto que o aprendiz passou a ser visto como um sujeito ativo no processo de ensinoaprendizagem.

Nos trabalhos de autores como Leite (2010), Morais (2012) e Soares (2003), consta que, a partir dos anos 1980, o conceito de alfabetização foi ampliado com as contribuições dos estudos sobre a psicogênese da aquisição da língua escrita, particularmente com os trabalhos de Emilia Ferreiro e Ana Teberosky e que, de acordo com esses estudos, o aprendizado do sistema de escrita não se reduziria ao domínio de correspondências entre grafemas e fonemas (a decodificação e a codificação), mas se caracterizaria como um processo ativo por meio do qual a criança, desde seus primeiros contatos com a escrita, construiria e reconstruiria hipóteses sobre a natureza e o funcionamento da língua escrita, compreendida como um sistema de representação.

Com a difusão das pesquisas sobre a Psicogênese da Língua Escrita, vimos nascer um forte discurso contrário ao uso dos tradicionais métodos de alfabetização e a defesa de uma prática que tomasse por base a teoria psicogenética de aprendizagem da escrita. Pregava-se a necessidade de possibilitar que as crianças se apropriassem do Sistema de Escrita Alfabética a partir da interação com diferentes textos escritos em atividades significativas de leitura e produção de textos, desde a Educação Infantil (ALBUQUERQUE, 2012, p.17).

Num contexto de inovações conceituais e práticas, os professores se depararam com inúmeros desafios que despertaram sua preocupação. As urgências impostas pelas transformações sociais penetraram os muros da escola, pressionando por mudanças efetivas nas práticas de ensino e trazendo importantes contribuições teóricas que emergiram dos trabalhos científicos. Tais conhecimentos, no entanto, não foram assimilados pelo sistema escolar (LEITE, 2010, p. 8), apesar de /.../ um esforço de convencimento dos alfabetizadores, mediante divulgação massiva de artigos, teses acadêmicas, livros e vídeos, cartilhas, sugestões metodológicas, relatos de experiências bem sucedidas e ações de formação continuada (MORTATTI 2006).

As discussões metodológicas voltaram à baila, com fortes críticas aos métodos sintéticos e analíticos que se alternaram ao longo da história pedagógica da alfabetização no Brasil, porém, apesar de o discurso construtivista ter assumido centralidade nos discursos sobre a alfabetização, não faltaram educadores que se 
mantiveram partidários dos tradicionais métodos de ensino, ainda que não "confessos" (MORTATTI, 2006, P. 10). Talvez esses educadores tenham insistido no uso dos tradicionais métodos de ensino, pela concretude de sua proposta, afinal, na época das cartilhas, havia um método, ainda que sem uma teoria sobre alfabetização, hoje há teorias, mas não se tem método (MENDONÇA e MENDONÇA, 2008, P.67). Esse apego à tradição metodológica também pode ser explicado pelo fato de os modelos sintéticos e analíticos terem feito parte da sua história escolar. Tendo sido alfabetizados por meio desses métodos, não se sentem seguros trilhando outros caminhos e resistem à mudança.

De toda forma, instalou-se um quadro de disputa entre os partidários do construtivismo e os defensores dos métodos de base sintética ou analítica. $O$ contato com as teorias construtivistas levou inúmeros educadores a recorrerem a novas alternativas para lidar com as dificuldades de seus alunos ou com os limites das tradicionais práticas de ensino, buscando alternativas para construir uma escola de qualidade (LEITE, 2010, p.8). Entretanto, mesmo aqueles que já estavam há anos lecionando, apresentaram muitas dificuldades para criar, em sala de aula, condições de produção, uso e circulação de textos que fossem similares àquelas vivenciadas nas situações reais de uso da escrita.

As questões de ordem didática ligadas à aprendizagem do sistema da escrita alfabética foram sendo anuladas, ao passo que era disseminada uma falsa ideia de que aprendizagem independe do ensino. Alguns professores, por medo de serem considerados tradicionais ou ultrapassados, mas também movidos pelo anseio de se adequarem à chegada das novas perspectivas teóricas, passaram, de acordo com Morais (2012, p.24), não só a questionar e negar o uso de tais métodos, mas a apostar numa "alfabetização sem metodologia", sem um plano de atividades intencionalmente concebidas para ensinar a escrita alfabética.

A crença de que o trabalho com diferentes textos seria condição suficiente para a compreensão do sistema de escrita alfabética converteu educadores que, precariamente formados e informados, muitas vezes continuavam a promover um ensino mecânico, fazendo uso de pseudotextos sem nenhuma relação de significância para os alunos. Sabemos que a interação com a escrita, seus usos e funções, seja de 
extrema relevância no processo de apropriação da escrita alfabética, porém acreditamos que:

/.../ apenas a interação com textos que circulam na sociedade não garante que os alunos se apropriem da escrita alfabética, uma vez que, no geral, essa aprendizagem não acontece de forma espontânea, mas exige um trabalho de reflexão sobre as características do nosso sistema de escrita. (ALBUQUERQUE, 2012, P.18)

Pode-se afirmar que o abandono dos chamados "métodos tradicionais de ensino" - categoria que inclui métodos sintéticos, analíticos e "mistos" - associado ao pouco conhecimento sobre a psicogênese e o papel do professor como mediador nesse processo, teve como consequência o apagamento do ensino sistemático da escrita. Assim, "A alfabetização passou a ocorrer de forma aleatória, com base na crença de que basta criar uma condição que possibilite o convívio com a escrita para que a criança se aproprie desse sistema simbólico e convencional" (LEITE, 2010, p.26)

Porém, por terem sido superficialmente estudados em cursos aligeirados de formação continuada e, até mesmo, mal compreendidos pelos educadores, esses estudos acabaram ocasionando um esvaziamento do processo de alfabetização e, como consequência dessa interpretação, algumas vezes equivocada, do que se chamou convencionalmente de "construtivismo", muitos educadores optaram pela ausência do ensino sistemático do sistema da escrita, entendendo que os educandos aprenderiam naturalmente a ler e a escrever através de sua imersão no mundo letrado e no universo de textos oferecido pela escola e pela vida em sociedade.

Um dos problemas derivados da leitura truncada da teoria da psicogênese da escrita, foi, portanto, a perda de especificidade do processo de alfabetização, e "em consequência disso, a alfabetização passou a ocorrer de forma aleatória, com base na crença de que basta criar uma condição que possibilite o convívio com a escrita para que a criança se aproprie desse sistema simbólico e convencional." (LEITE, 2010, P. 26)

Além disso, por postular que o processo de produção do conhecimento é, teoricamente, centrado no sujeito - no caso, o aluno -, conferiu-se ao professor uma condição periférica no processo de ensino-aprendizagem, já que, de acordo com um dos equívocos divulgados, não seria necessário ensinar, porque a criança aprenderia sozinha: "Dizia-se, também, que o professor não precisava desenvolver um trabalho 
sistemático de alfabetização, pois deveria exercer a função de "mediador" do conhecimento (papel que não ficava claro aos professores)." (MENDONÇA e MENDONÇA, 2008, p. 61).

Dessa forma, toda responsabilidade pelo processo de ensino-aprendizagem foi atribuída ao aluno. O que acarretou ainda mais dificuldades na apropriação da leitura e da escrita que requer um trabalho sistemático com objetivos determinados, com carga horária diária, concentração, esforço, persistência e determinação (MENDONÇA e MENDONÇA, 2008, p.61). Na verdade,

O professor tem uma tarefa a realizar em sala de aula e não pode ser um mero espectador do que faz o aluno ou um simples facilitador do processo de aprendizagem, apenas passando tarefas. Cabe a ele ensinar também e, assim, ajudar cada aluno a dar um passo adiante e progredir na construção de seus conhecimentos. (ROJO, 1998, p. 69)

As profundas mudanças sociais e econômicas ocorridas promoveram transformações teóricas e pedagógicas no campo da alfabetização e também abriram espaço para uma rápida difusão do conceito de letramento no Brasil, isso deslocou a centralidade da escrita do seu entendimento como código para sua compreensão como um processo simbólico. Mais uma vez, testemunhamos um avassalador "amor" teórico que tomou a cena e tornou-se hegemônico, como discutiremos a seguir.

\section{O "discurso do letramento" e a "desinvenção da alfabetização"}

Diante das inúmeras críticas que foram feitas, desde a década de 1960, ao modelo tradicional de alfabetização, foi praticamente imediata à incorporação do conceito de letramento ao meio acadêmico e educacional. Esse conceito somou-se aos ideais e concepções construtivistas, também implementados no cenário educacional brasileiro na década de 80, e ambos pareciam um caminho perfeito para que se alcançasse a tão sonhada erradicação do analfabetismo anunciada pela constituição de 1988 (COLELLO, 2010, p.75). Segundo Ângela Kleiman,

Na metade da década de 1980, no Brasil, vários pesquisadores que trabalhavam com as práticas de uso da língua escrita em diversas esferas de atividades sentiram falta de um conceito que se referisse a esses aspectos sócio-históricos dos usos da escrita, sem as conotações sobre o ensino e escola associados à palavra alfabetização. Emergiu, então, na literatura especializada, o termo letramento, para se referir a um conjunto de práticas de uso da escrita que vinham modificando profundamente a sociedade, mais amplo do que as práticas escolares de uso da escrita, incluindo-as, porém (KLEIMAN, 2005, P.21). 
O conceito de letramento, junto às concepções do construtivismo, foi ganhando cada vez mais espaço, por materializar as demandas de uma sociedade na qual a apropriação da escrita, tratada apenas como uma tecnologia, já não era suficiente para a efetiva participação do indivíduo nas diversas práticas que exigiam seu domínio

O discurso sobre "alfabetizar letrando" se tornou extremamente potente, porém, infelizmente, em muitos casos, apenas tem servido para mascarar a ausência de um ensino reflexivo e sistemático do sistema da escrita alfabética, já que segundo Morais (2012, p.24), a má interpretação da teoria da psicogênese da escrita somou-se de forma também equivocada à crescente hegemonia do discurso do letramento. Dessa forma,

\begin{abstract}
... criamos certa ditadura do texto (segundo a qual seria proibido trabalhar com unidades menores, como palavras ou sílabas), como se fosse verdade que a maioria das crianças "descobre", por conta própria e sem instrução sistemática, como a escrita alfabética funciona e quais são suas convenções. Na realidade, esta "descoberta sem ensino" não ocorre para a grande maioria das crianças dos grupos sociais favorecidos. Mesmo a maioria dos filhos da classe média e da burguesia só se alfabetiza recebendo um ensino específico sobre a escrita alfabética (MORAIS, 2012, P. 25)
\end{abstract}

Nesse contexto de novas orientações para o ensino, que enfatizavam a necessidade de se enfocar os usos e funções sociais da escrita, o trabalho com os gêneros textuais passou a ser visto como condição para que o aluno tivesse acesso às práticas de produção, uso e consumo de textos que circulam em diferentes esferas sociais. Porém, alguns professores continuaram privilegiando a leitura textos descontextualizados e artificiais, ao passo que desconsideravam os aspectos específicos da alfabetização.

Esse duplo movimento comprometeu o processo de aprendizagem da leitura e da escrita e também a inserção plena dos estudantes nas práticas sociais. A "ditadura do texto", associada ao "discurso contra os métodos", que foi hegemônico nas últimas décadas, levou ao que Magda Soares (2003, p.1) chamou de "desinvenção da alfabetização". Para ela, os equívocos e as falsas inferências, anteriormente mencionados, levaram os movimentos de alfabetização e letramento a se confundirem, com prevalência deste último e perda de especificidade do primeiro. Isso pode ser considerado como uma das causas do fracasso em alfabetização que hoje ainda se verifica em muitas escolas brasileiras. Um desses equívocos é a cisão entre os dois processos, baseada na percepção de que a alfabetização seria anterior ao letramento, tomado como uma prática eminentemente escolarizada e singular. 
Angela B. Kleiman (2005, p.14) sustenta que a alfabetização é necessária para que alguém seja considerado plenamente letrado, embora não seja suficiente. Sendo assim, ainda segundo a autora, alfabetização é inseparável de letramento. Magda Soares (2003, p. 7) também destaca essa interdependência entre alfabetização e letramento, pois:

/.../a alfabetização desenvolve- se no contexto de e por meio de práticas sociais de leitura e de escrita, isto é, através de atividades de letramento, e este, por sua vez, só se pode desenvolver no contexto da e por meio da aprendizagem das relações fonema-grafema, isto é, em dependência da alfabetização.

Mesmo com tantos problemas, no entanto, é indubitável que houve pequenos avanços. Segundo Leite (2010, p.17), muitos educadores superaram o modelo cartilhesco de alfabetização, que desconsiderava a peculiar lógica do desenvolvimento cognitivo do aluno, ou, ao menos, começaram a questionar e até negar o uso de tais instrumentos e buscar caminhos mais coerentes.

Consideramos que a "reinvenção da alfabetização" - que já se encontra lentamente em curso - implica no resgate dos fundamentos das diferentes perspectivas teóricas que buscam compreender como se dá a aprendizagem do sistema da escrita alfabética, entre as quais destacamos nesse texto a teoria da psicogênese da língua escrita, e na compreensão dos letramentos sociais (STREET, 2014), que também foram deixados de lado pela escola.

É preciso levar em consideração o fato de que que muitos dos alunos da rede pública vivenciam eventos de letramento que não correspondem ao modelo valorizado pela escola. Conforme explicita Terzi (2006, p.53), embora vivamos em uma sociedade letrada, na qual é quase impossível não entrar em contato com a escrita, a quantidade e a qualidade desse contato dependem das condições de vida e das características da comunidade em que as pessoas vivem. Além disso, Terzi (2006, p.44) evidencia que as habilidades culturalmente determinadas pela escola são aquelas encontradas nas famílias de classe média, conforme mencionamos anteriormente.

Heath (apud TERZI, 2006) sinaliza esse desencontro, ao afirmar que cada comunidade tem sua própria orientação de letramento e que o tipo de orientação da classe média não pode ser tomado como modelo universal nas sociedades ocidentais. Essa pesquisadora também afirma que o desconhecimento da orientação de 
letramento do grupo social a que pertence a criança por parte da escola pode impedir a compreensão do desenvolvimento e das necessidades que ela apresenta. Desse modo, há uma tendência a que a criança oriunda de grupos sociais desfavorecidos economicamente seja considerada abaixo do padrão de letramento escolar. Assim, sua diferença sociocultural é tomada por tal modelo escolar como um fator que a torna incapaz. Como a escola desconsidera as características de letramento da comunidade desses alunos, acaba por se sobrepor a elas, ou por impor uma orientação diferente, quando, deveria apresentá-los à escrita, e aos seus usos e funções no conjunto da sociedade. A perspectiva dos letramentos sociais é fundamental para que os estudantes possam compreender o funcionamento do sistema da escrita em termos socioculturais e compreender os textos que circulam na sociedade.

Por isso, de acordo com Silvia Colello (2010, p.85), mais do que estar alfabetizado, importa saber o que o sujeito pode fazer com o conhecimento sobre a língua. De fato, ainda é preciso aprender a ler e a escrever, mas a alfabetização, entendida como aquisição de habilidades de mera decodificação e codificação da linguagem escrita e as correspondentes dicotomias analfabetismo $X$ alfabetização e analfabeto $X$ alfabetizado não bastam mais. É preciso hoje, também saber utilizar a leitura e a escrita de acordo com as contínuas exigências sociais, e esse algo mais é o que se vem designando "letramento" (MORTATTI apud COLELLO, 2010, p.85). Trata-se de uma mudança substancial, pois

\footnotetext{
Para alfabetizar letrando, é preciso que o professor assuma certas posturas, de modo que a prática pedagógica seja conduzida no sentido de viabilizar a formação de um sujeito que não apenas decodifica/ codifica o código escrito, mas que exerça a escrita nas diversas situações sociais que the são demandadas (MACIEL e LÚCIO, 2008, p.32).
}

Essa perspectiva é perfeitamente conciliável com as teorias da psicogênese, pois, segundo Emília Ferreiro (2011, p.21), "é imperioso (porém, nada fácil de se conseguir) restabelecer, no nível das práticas escolares, uma verdade elementar: a escrita é importante na escola, porque é importante fora da escola, e não o inverso."

Colello (2010, p.77) acredita que, mais do que garantir aos docentes certa apropriação metodológica, a construção de uma escola em prol da formação de sujeitos leitores e escritores no contexto da sociedade letrada depende de uma reorientação do ensino. É urgente que os professores reflitam sobre o caráter cultural 
da escrita e seu processo de apropriação, compreendendo seu caráter multifacetado, significativo, complexo e plural. Para ela,

\begin{abstract}
O ensino da língua escrita abarca uma infinidade de saberes, habilidades, procedimentos e atitudes que se constroem em longo prazo pela possibilidade de, entre tantas coisas, conhecer letras e expressar sentimentos, decodificar sinais e interpretar o mundo, selecionar informações e articular ideias, escrever palavras e se relacionar com o outro, conhecer as arbitrariedades do sistema e aprimorar esquemas de organização do pensamento, desenhar traçados convencionais e recriar as dimensões humanas de tempo e espaço, respeitar normas e constituirse como sujeito autor, adestrar os olhos e viajar por meio da leitura, dominar a mão e usufruir o direito à palavra (COLELLO, 2010, p.77).
\end{abstract}

Apesar de mudanças significativas terem ocorrido nas práticas dos professores, que estão se tornando progressivamente mais cientes de que o aprendizado da leitura e da escrita não pode estar desvinculado dos sentidos que construímos e dos usos que fazemos do ler e do escrever, as tentativas de se construir caminhos para a alfabetização na perspectiva do letramento ainda têm esbarrado em diversas dúvidas e dificuldades.

As dificuldades enfrentadas na "reinvenção da alfabetização" têm aberto espaço para a tentativa, por parte de alguns pesquisadores, de apresentar "novas" propostas de alfabetização baseadas em antigos métodos (MORTATTI, 2006, p.12). Além disso, têm se tornado frequentes as reportagens publicadas em revistas de grande circulação que criticam o ensino da leitura e escrita com base em uma abordagem construtivista de alfabetização, afirmando ser tal abordagem responsável pelo baixo índice de leitura apresentado por nossos educandos no processo de avaliação (ALBUQUERQUE, 2012, p.19).

Entendemos, no entanto, que não é do retorno dos métodos tradicionais que precisamos, mas de um ensino que entenda alfabetização e letramento como processos distintos, que carregam consigo suas especificidades, mas que são indissolúveis e interdependentes, sendo, hoje, na sociedade na qual vivemos, impossível a formação de sujeitos críticos sem a interseção entre esses processos.

Além disso, o exame de teorias e práticas também permite-nos concluir que não existe um método superior capaz de alfabetizar todas as crianças, pois cada criança é um ser único, com suas especificidades, gostos, preferências e valores que também influenciam diretamente o processo de ensino-aprendizagem. Além disso, para alfabetizar uma criança, mais importante do que a escolha de um método ou 
metodologia específica, é, primeiramente, a compreensão do valor atribuído por ela à escrita.

\section{Autonomia e autoria na formação de alfabetizadores}

Dadas todas as considerações anteriores, enfatizamos a necessidade de que os professores alfabetizadores tenham oportunidades de formação adensada e fundamentada que Ihes permita desenvolver conhecimentos acerca das teorias sobre a aprendizagem do sistema da escrita e sobre os letramentos numa perspectiva sociocultural para fazerem suas opções didáticas com autonomia.

Concordamos com Botero (2008, p.67), quando afirma que não é possível que nenhum processo de ensino se realize de forma plena se o professor desconhece 0 que acontece com o aluno no processo de aprendizagem. Sendo assim, a qualidade do ensino nos primeiros anos escolares relaciona-se intimamente com a formação do professor. Tal constatação nos leva a reconhecer que um ensino de qualidade requer um docente qualificado, que possa exercer sua autonomia e criar estratégias adequadas ao contexto em que atua.

Para isso, a formação de professores alfabetizadores precisa romper com os paradigmas e criar espaços e processos radicalmente diferentes de formação efetivamente continuada, fundando-se nos seguintes pilares:

1 - Organização de currículos locais de formação centrados nas práticas e na análise das práticas, conforme a proposta defendida por Nóvoa (1992), tomando como ponto de partida as necessidades, os desejos e as potencialidades de cada coletivo docente;

2 - Desenvolvimento de estudos aprofundados e integrados de teorias sobre a aprendizagem do sistema alfabético e sobre os letramentos, em diferentes abordagens, numa perspectiva plural;

3 - Realização sistemática de experiências de teoria-na-prática com a criaçãoimplementação-avaliação de estratégias pedagógicas para o ensino da leitura e da escrita situadas no contexto específico de cada escola, elaborando didaticamente as teorias estudadas de maneira a transformá-las tendo em consideração a cultura local. 
Acreditamos que, para a implementação dessa proposta as parcerias entre universidade e escola básica poderiam ser pensadas em temos de hierarquias horizontais e de projetos locais, tendo em vista que as políticas de larga escala e o modelo de cursos top-down não seriam adequados à proposta que apresentamos. Desse modo, para favorecer a criação de espaços de formação em que os professores alfabetizadores possam exercer plenamente sua agência e autoria, defendemos a valorização da diversidade dos espaços escolares e dos sujeitos que neles circulam e o reconhecimento da pluralidade de abordagens teóricas e metodológicas que caracterizam os estudos sobre a aprendizagem do sistema da escrita e as práticas sociais de letramento.

Entendemos que a formação de alfabetizadores nessa perspectiva pode contribuir para a superação dos problemas decorrentes do afastamento entre teorias e práticas no processo de alfabetização e para que cada professor possa criar sua metodologia de trabalho, realizando a apropriação e a elaboração didática das teorias e adequando-as ao contexto sociocultural em que atua.

Referências

ALBUQUERQUE, E. B. C. Currículo no ciclo de alfabetização: Princípios gerais. In: Pacto Nacional pela alfabetização na idade certa - Currículo na alfabetização: concepções e princípios. Brasília: MEC, 2012.

BOTERO, L. B. Enseñando a leer: Teoria, prática e intevención. Bogotá: Grupo Editorial Norma, 2008.

MACIEL, F. I. P.; LÚCIO, I. S. Os conceitos de alfabetização e letramento e os desafios da articulação entre teoria e prática. In: CASTANHEIRA, M. L. et. Al. Alfabetização e letramento na sala de aula. Belo Horizonte: Autêntica Editora: Ceale, 2008.

FERREIRO, E. Com todas as letras. São Paulo, 2011.

FREIRE, P. Educação como prática da Liberdade. Rio de Janeiro: Paz e Terra, 1967.

KLEIMAN, A. B. Preciso "ensinar" o letramento? Não basta ensinar a ler e a escrever? Campinas, Cefiel/ IEL/Unicamp, 2005.

LEITE, S. A. S.; COLELLO, S. M. G. Alfabetização e letramento. São Paulo: Summus, 2010. 
MENDONÇA, O. S. e MENDONÇA, O. C. Alfabetização: Método Sociolinguístico: Consciência social, silábica e alfabética em Paulo Freire. São Paulo: Cortez Editora, 2008.

MORAIS, A. G. Sistema de escrita alfabética. São Paulo: Melhoramentos, 2012 [Como eu ensino]

MORTATTI, M. R. L. História dos Métodos de Alfabetização no Brasil. Brasília, 2006.

Nóvoa, A. (coord). Os professores e a sua formação. Lisboa: Dom Quixote. 1992.

SOARES, M. Letramento e alfabetização: as muitas facetas. Minas Gerais, 2003 . Letramento: um tema em três gêneros. Belo Horizonte: Autêntica, 2014.

STREET, B. V. Letramentos Sociais: abordagens críticas de letramento no desenvolvimento, na etnografia e na educação. São Paulo: Parábola Editorial, 2014. TERZI, S. B. A construção da leitura: uma experiência com crianças de meios iletrados. Campinas, São Paulo: Pontes, 2006.

A oralidade e a construção da leitura por crianças de meios iletrados.

Campinas, São Paulo: mercado de Letras, 1995. 